\section{The Liaison Society for Ethics Committees of Medical Schools in Japan}

\author{
KAZUMASA HOSHINO
}

There are 80 medical schools in Japan. Each medical school has established independently one ethics committee based upon their own ideas about the purposes, composition of membership, and functions. Some committees are concerned only with ethical evaluations of biomedical research in human subjects, but the majority function similarly to the hospital ethics committee; the healthcare ethics committees, or the combined type in the United States.

In July 1988, the chairmen of ethics committees in three medical schools sent a letter to all medical schools proposing that a certain kind of an organization be set up to communicate among the 80 medical schools for exchange of information, opinions, and other important matters concerning bioethical issues.

Upon receipt of favorable responses from the majority of schools, the organizing meeting was held in Tokyo on 15 December 1988, and serious discussion took place for several hours. Finally, the following statements were agreed upon by the participants at the meeting. I was then elected as the Executive Director of the Society.
1. The Liaison Society of Ethics Committees in Medical Schools in Japan is established in order to communicate and create understanding amongst all the ethics committees of 80 medical schools in Japan through the exchange of information, experiences, and opinions.

It is agreed that the Society must not be an organization to make resolution of any unified opinions.

2. The membership of the Society is a representative of each ethics committee of all medical schools in Japan.

3. The Society must hold semiannual meetings every year and undertake things necessary for fulfilling the purposes of the Society.

4. The fund for operating the Society depends upon the income from attendance fees at the semiannual meetings, donations, and other.

The first annual meeting was held at the Kyoto University Hall on 13 February 1989, and the sixth semiannual meeting was held on 19-20 October 1991 at the Kitasato University Faculty of Medicine. The Society also supported five International Bioethics Symposia held under the auspices of the Foundation for Advancement of International Sciences, Inc. (President: Mr. Hirokichi Yoshiyama). 